\title{
Profile of risk factors for noncommunicable diseases in major cities of Afghanistan: WHO STEPwise approach
}

Khwaja Mir Islam Saeed, ${ }^{1}$ Muhammad Hafiz Rasooly ${ }^{2}$ and Malalai Nejaby ${ }^{3}$

${ }^{1}$ Grant and Contract Management Unit; ${ }^{2}$ Influenza Surveillance Unit, Evaluation and Health Information System, Ministry of Public Health, Kabul, Afghanistan (Correspondence to: Khwaja M.I. Saeed: kmislamsaeed@gmail.com). ${ }^{3}$ Helping Mothers and Children Thrive Project (HEMAYAT), Johns Hopkins Program for International Education in Gynaecology and Obstetrics, Kabul, Afghanistan.

\begin{abstract}
Background: Noncommunicable diseases (NCDs) are a major public health problem worldwide. Despite improvement in the health situation, Afghanistan's health indicators are the worst in the Region. About 37\% of Afghan adults die due to NCDs.

Aims: We aimed to estimate the proportion of major risk factors for NCDs in Afghanistan.

Methods: We analysed the dataset of studies conducted in 5 provinces, Kabul, Balkh, Hirat, Nangarhar and Kandahar, during 2013-2015, using the WHO STEPwise approach to NCD surveillance. This involved multistage cluster sampling from urban citizens aged 25-70 years. EpiInfo, version 7, and SPSS, version 20, were used for data management.

Results: In total, 5897 records were included in the analysis; 54\% were females. Mean age was 39.56 (standard deviation12.29) years; illiteracy rate was $61.5 \%$ and $83.2 \%$ were married. Smoking and snuff use was $8 \%$ and $11.1 \%$ respectively. On average the subjects were consuming fruits 2.76 and vegetable 3.85 days per week. Overweight, general and abdominal obesity was 19\%, 33.7\% and 57.1\% respectively. Typically, 32.4\% had high blood pressure and $12.5 \%$ had high blood sugar.

Conclusions: The modifiable risk factors of NCDs were prevalent in the major cities of the country. Their identification is vital in attempting to focus on prevalence of NCDs in urban cities. Tailored interventions are needed to focus on NCDs in Afghanistan.
\end{abstract}

Keywords: noncommunicable diseases, risk factors, Afghanistan, STEPwise

Citation: Saeed K; Rasooly M; Nejaby M. Profile of risk factors for noncommunicable diseases in major cities of Afghanistan: WHO STEPwise approach. East Mediterr Health J. 2020;26(4):388-399. https://doi.org/10.26719/emhj.20.005

Received: 12/10/17; accepted: 28/11/18

Copyright (C) World Health Organization (WHO) 2020. Open Access. Some rights reserved. This work is available under the CC BY-NC-SA 3.0 IGO license (https://creativecommons.org/licenses/by-nc-sa/3.o/igo).

\section{Introduction}

Afghanistan is a landlocked country in south central Asia. Administratively, the country is divided into 8 geographical regions, 34 provinces and 398 administrative districts. The 2014/15 estimated population of the country was 26.5 million (1). The most recent figures from 2015, though better than the previous (2003) data, estimate a total fertility rate of 5.3 children per women and an infant mortality rate of 55 per 1000 live births (2). About 4 decades of war in Afghanistan has devastated the country's infrastructure, economy and social services, resulting in a low quality of life. The Taliban rule compounded the suffering of women by curtailing their access to already limited health services. Almost $75 \%$ of the districts in Afghanistan lacked maternal and child health services and most women gave birth devoid of the presence of a skilled birth attendant $(3,4)$. Moreover, opiate production increased in the country significantly and led to destabilization of the formal economy and the political situation of Afghanistan. According to a 2015 UN report, opium production in Afghanistan accounted for an estimated $85 \%$ of global production (5).

Despite improvement in the health situation, Afghanistan's health indicators are the worst in the region. Above all, about $37 \%$ of Afghan adults die due to noncommunicable disease (NCD) (6). Noncommunicable diseases are medical conditions with long duration and slow progression. Currently, NCDs constitute a major challenge with adverse social and economic consequences, particularly in low- and middle-income countries (7). The 4 priority NCDs are cardiovascular diseases, cancer, chronic respiratory disease and diabetes (8). For many years the world has been expending efforts to prevent and control infectious diseases, malnutrition and maternal and perinatal conditions whereas the epidemiological transition indicates the decline of infectious diseases and the upsurge in chronic NCDs (9).

Mortality due to NCDs contributed to $70 \%$ of global deaths in 2017 and the documented prevalence in 2008 was $63 \%(10-12)$. Recently, the World Health Organization (WHO) has reported that NCDs kill 40 million people a year, and almost $80 \%$ of NCD deaths (32 million) occur in low- and middle-income countries. Cardiovascular diseases account for most of these deaths at 17.7 million annually, followed by cancer (8.8 million), respiratory diseases (3.9 million) and diabetes (1.6 million). These 4 groups of diseases account for $82 \%$ of all NCD deaths. Tobacco use, physical inactivity, the harmful use of alcohol and unhealthy diets together increase the risk of dying from an NCD (13). Furthermore, beyond the health 
impact, NCDs impose an economic burden on health systems, skewed towards the low-income countries (14-15). In countries of the WHO Region for the Eastern Mediterranean, up to $50 \%$ of deaths due to NCDs occur before the age of 60 years compared with less than $10 \%$ in Western Europe (16). Nearly 54\% of deaths occur due to NCDs in the South-East Asia Region (17). Key factors that greatly contribute to the progress of NCDs have been identified and considered (18). The health goal is to reduce mortality from NCDs by $25 \%$ by 2025 ; this is "the 25 by 25 goal" (19).

According to WHO, NCDs are estimated to account for $62 \%$ of total deaths in Tajikistan, 79\% in Uzbekistan, $50 \%$ in Pakistan and $76 \%$ in the Islamic Republic of Iran and Turkmenistan, all countries neighbouring Afghanistan, conversely NCDs account for $37 \%$ of total deaths in our country (20). Similar results were found in the 2010 Afghanistan mortality survey: $33.3 \%$ of all deaths in the country were attributed to NCDs (6). Furthermore, WHO estimates the number with diabetes, for instance, is expected to rise nearly threefold in 2030 compared with 2000 (21). Among men aged $\geq 15$ years in Kabul, the prevalence of smoking was 35\% (22), while a 2012 report on prevalence and risk factors of NCDs among the older adult population (aged $\geq 40$ years) in Kabul reported the prevalence of diabetes mellitus as $13.3 \%$, obesity $31.2 \%$ and hypertension $46.2 \%$ (23). The national policy for NCDs has recently been developed by Ministry of Public Health (24).

This study aimed to estimate the prevalence of risk factors for chronic NCDs in the urban population in 5 main cities in Afghanistan.

\section{Methods}

\section{Study setting and design}

Using the WHO STEPwise approach, a series of cross-sectional studies were conducted in urban settings of major provinces in Afghanistan: Jalalabad city (May-June, 2013), Mazar-e-Sharif (April to May, 2015), Herat city (May-June, 2015), Kandahar city (October-November, 2015) and Kabul city (November 2015). All permanent residents and household members aged 25-70 years, including men and women, who gave consent to participate were included in the study. Temporary residents $(<$ 6 months), inhabitants of institutionalized settings and insecure areas were excluded. We used an adapted WHO STEPwise instrument; this prescribes 3 steps for measuring NCD risk factors: STEP I measures behavioural risk factors, STEP II covers physical measurements and STEP III measures biological risk factors (25-27). The WHO STEPS tool was adapted for the Afghanistan context. For instance, the part regarding alcohol consumption was removed and some questions regarding use of mouth snuff (called naswar locally), which is common in the country, were added. The addition of liquid and solid cooking oil, which is used in the kitchen, was another modification. Some other questions were also modified to easily reflect the meaning without losing the content. The research team translated the data collection tools into local lan- guages (Dari and Pashto). The tools were tested in Kabul before actual data collection were started.

\section{Sampling techniques and strategy}

Cluster sampling was used as a suitable strategy to approach the households. Assuming the highest proportion (50\%), 95\% confidence interval (CI) and margin of error of $5 \%$, a sample size of 385 was calculated. However, considering the frequency of risk factors such as smoking, physical activity, dietary habits and other factors and the design effect of cluster sampling, the final sample size was increased to 600 and finally to 1200 (deff $=2 \times 600$ ) for each city. After completion of data collection and cleaning of the data, 1200 participants in Jalalabad, 1231 in Mazare-Sharif, 1129 in Hirat, 1165 in Kandahar and 1172 in Kabul were included in the final analysis.

For more than 4 decades no census has been conducted in the country and a complete list of villages was not available. The 2015 Expanded Programme on Immunization (EPI) lists of clusters were obtained from EPI unit in provinces and were used as the sampling frame. This frame was used for immunization by the Ministry of Public Health in Afghanistan. Two-stage cluster sampling was used. In the first stage, random sampling was accomplished using Excel; from the EPI list, 4 clusters were selected in Jalalabad, 5 in Mazar-e-Sharif, 16 in Hirat, 7 in Kandahar and 5 in Kabul using random numbers from Excel. In the second stage, the overall sample of 1200 households was divided among these selected areas proportionate to the number of households in each cluster/area. Based on the frequency and size of each selected cluster, households were selected using a systematic random sampling technique.

\section{Variables and data collection}

The STEPwise approach has a standard questionnaire, which was adapted and used by the interviewers and which covered information on demographic, behavioural and physical measurements. The study variables included sociodemographic characteristics such as age, sex, level of education, occupation, income and marital status; behavioural factors such as physical activity, consumption of fruits and vegetables, use of cooking oil, smoking and naswar (tobacco snuff) use; and physical measurements such as blood pressure, weight, height, waist circumference and body mass index (BMI), biological components such as blood sugar, triglycerides and cholesterol. From height and weight, BMIs was calculated: $\geq 30.0 \mathrm{~kg} / \mathrm{m}^{2}$ was considered obese, $25.0-29.9 \mathrm{~kg} / \mathrm{m}^{2}$ overweight and $18.5-24.9 \mathrm{~kg} / \mathrm{m}^{2}$ normal weight (28). A waist circumference of $94 \mathrm{~cm}$ for men and $80 \mathrm{~cm}$ for women was defined as central obesity (29). Systolic blood pressure $\geq 140 \mathrm{mmHg}$ and/or diastolic pressure $\geq 90 \mathrm{mmHg}$ were considered as hypertensive. Furthermore, systolic blood pressure of $<120 \mathrm{mmHg}$ and diastolic pressure of $<80 \mathrm{mmHg}$ were considered normal while the group between these 2 limits was considered as prehypertensive (30). Those who smoked at the time of the survey were considered smokers and included in proportion. Alco- 
hol consumption was removed from the questionnaire due to the very low prevalence and high sensitivity for respondents. Strong and moderate physical activity was defined as those activities which increase the heart rate and breathing intensively and moderately for 10 minutes (see the STEPS approach for details). Local health workers were recruited and trained as data collectors. A field test was conducted and glitches during data collection were identified and rectified. Anthropometric measurements were determined using an electronic weighing scale and plastic measuring tape. Blood pressure was measured using an aneroid sphygmomanometer 3 times and the average was used for proportion. Finally, blood samples were collected on the spot or the next morning after the respondent had fasted for 10-12 hours. They were transported in cold boxes $\left(2-8^{\circ} \mathrm{C}\right)$ from the field to the Central Public Health Laboratory in Kabul using Cryovials. The samples were coded with the ID number of the questionnaire. On arrival in the Central Public Health Laboratory, all serum samples were stored at $-80^{\circ} \mathrm{C}$ and later on were tested for triglyceride, cholesterol and glucose using spectrophotometric method. A fasting blood sugar of $\geq 126 \mathrm{mg} / \mathrm{dL}$ was considered as diabetes mellitus (31). The cut-off for total biochemical markers was determined as: cholesterol $190 \mathrm{mg} / \mathrm{dL}$, low density lipoprotein (LDL) 100 $\mathrm{mg} / \mathrm{dL}$, high density lipoprotein (HDL) for males $40 \mathrm{mg} /$ $\mathrm{dL}$ and for females $50 \mathrm{mg} / \mathrm{dL}$, and triglycerides $150 \mathrm{mg} /$ dL. Data management and analysis were carried out using EpiInfo, version 7 and SPSS, version 20.

According to the plan, 2 days training was conducted for those administering the survey followed by a fieldbased session where they had a chance to complete the questionnaire, measure blood pressure and waist circumference and practise taking blood samples from adults under field conditions.

A household was defined as a group of people who share the same food pot (not the same roof). In each household the interviewer enumerated all persons who were eligible for our study based on the inclusion criteria. In households with more than one eligible person, we used a lottery system to select the respondent for this survey. In cases of refusal, which was less than $5 \%$, the interviewer approached the next household. This method provided an equal chance of each member of the household being selected.

\section{Ethical considerations}

The protocol was reviewed by the Institutional Review Board of the Ministry of Public Health and a blanket approval was issued. Informed consent was obtained from each individual before the interview. The results of physical and biochemical measurements were communicated to the participants and the confidentiality of the information was maintained. All blood samples were stored at $-80^{\circ} \mathrm{C}$ in the Central Public Health Laboratory after completing biochemical measurements for further testing. All collected data, hard and soft, were kept confidential in a locked cupboard and a password-protected computer.

\section{Data analysis}

Descriptive analysis was done using mean and proportions to explain and describe the NCDs and risk factors. Statistical tests such as Student t-test and chi-squared were used to identify statistical significance whenever needed. The available dataset from each urban setting was used to identify the proportion of related risk factors for NCDs in each of the 5 cities. Later on the datasets were integrated and the pooled proportion was calculated from all datasets. The studies were conducted in a series of time intervals but the research team, data collection tool and protocols remained the same. However, as it is not conducted in a snapshot of time, this combined frequency should be interpreted cautiously. Furthermore, we weighted the data to make it comparable with the original population, which is published by the Central Statistical Office in Afghanistan. Both weighted unweighted results are presented for comparison.

\section{Results}

\section{Behavioural risk factors: STEP 1}

Of the total of 5897 respondents recruited in 5 cities, 2712 were male $(46 \%)$. The average age of respondents was 39.6 [standard deviation (SD) 12.3] years. Overall, $38 \%$ of participants were literate; the highest literacy level (50\%) was recorded in Kabul and the lowest (27\%) in Kandahar. Around a quarter of the study participants were earning $\geq 10000$ Afghanis (US\$175) a month (Table 1). The majority $(83.5 \%)$ were married; only $7.7 \%$ were single. On average, the selected households comprised 3.1 adults eligible for this study, of whom one in each selected household was interviewed. It should be noted that due to missing values (responses) in some variables the subtotals do not always reflect the total number of participants.

We found overall $8.0 \%$ of the participants were cigarette smokers and 11.1\% were using naswar, however, usage was very low in females ( $2.7 \%$ and $2.5 \%$ respectively) compared with males ( $14.1 \%$ and $21.1 \%$ respectively). There was a statistically significant difference in tobacco use between males and females $(P<0.01)$. The highest level of naswar use was in the older population (55+ years) while the younger generation were more likely to smoke cigarettes.

On average, the participants consumed fruits 2.76 days per week and vegetables 3.85 days per week. On a typical day they consumed 1.4 servings of fruits and 1.9 servings of vegetables. More than two thirds (71.1\%) consumed fruits $\leq 3$ days per week and close to half $(49.5 \%)$ consumed vegetables $\leq 3$ days per week. Generally, consumption of fruits was slightly higher in the youngest and oldest groups (Table 2). The highest proportion of adult citizens consuming vegetables $\leq 3$ days a week was in Jalalabad (in all age groups); the lowest percentage was recorded in Hirat.

For other food groups (data not shown), 10.5\% of all study participants consumed red meat less than 2 days per week; $4.6 \%$ consumed chicken and $35.9 \%$ consumed rice more than 3 days per week. The use of table salt was 


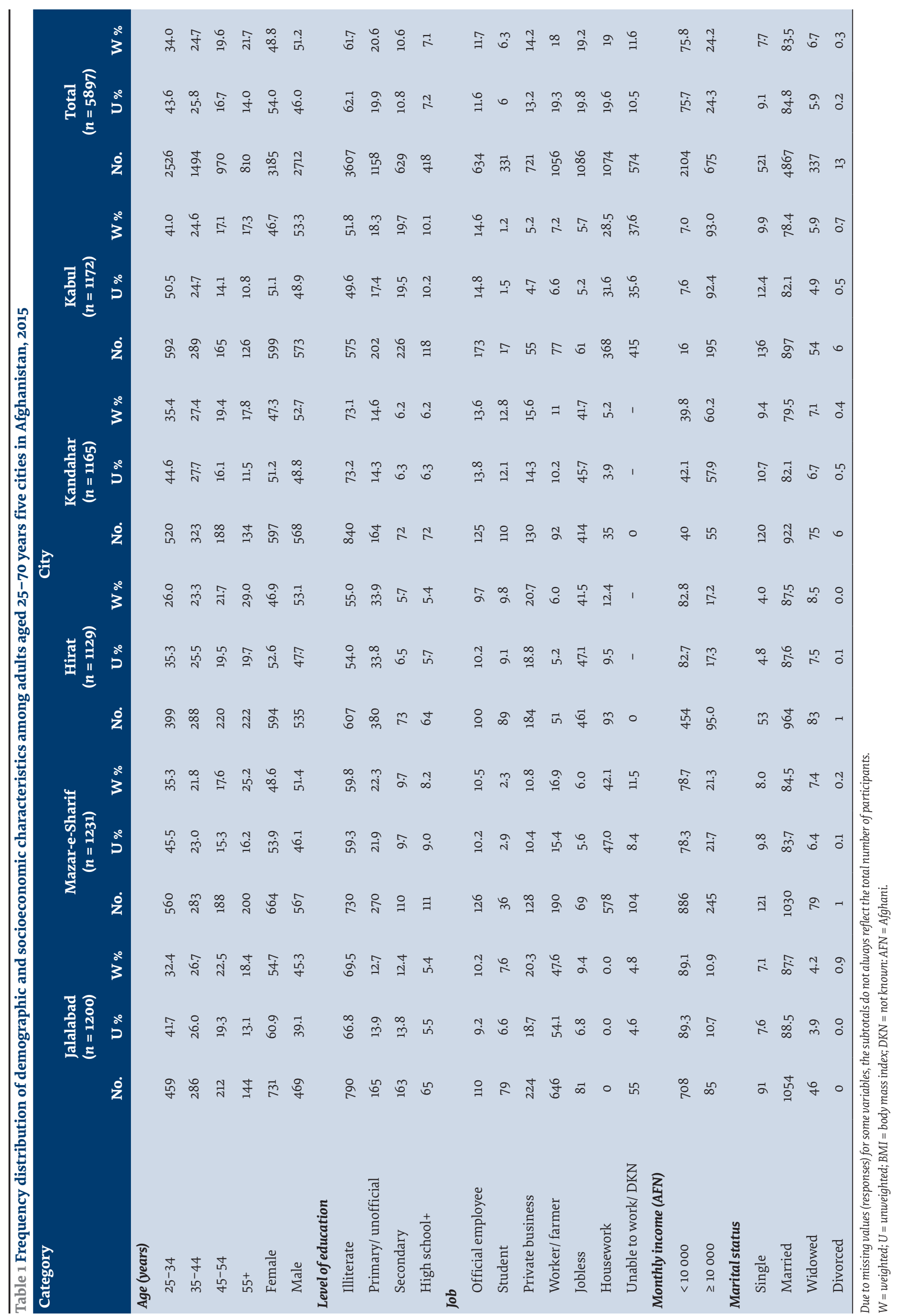




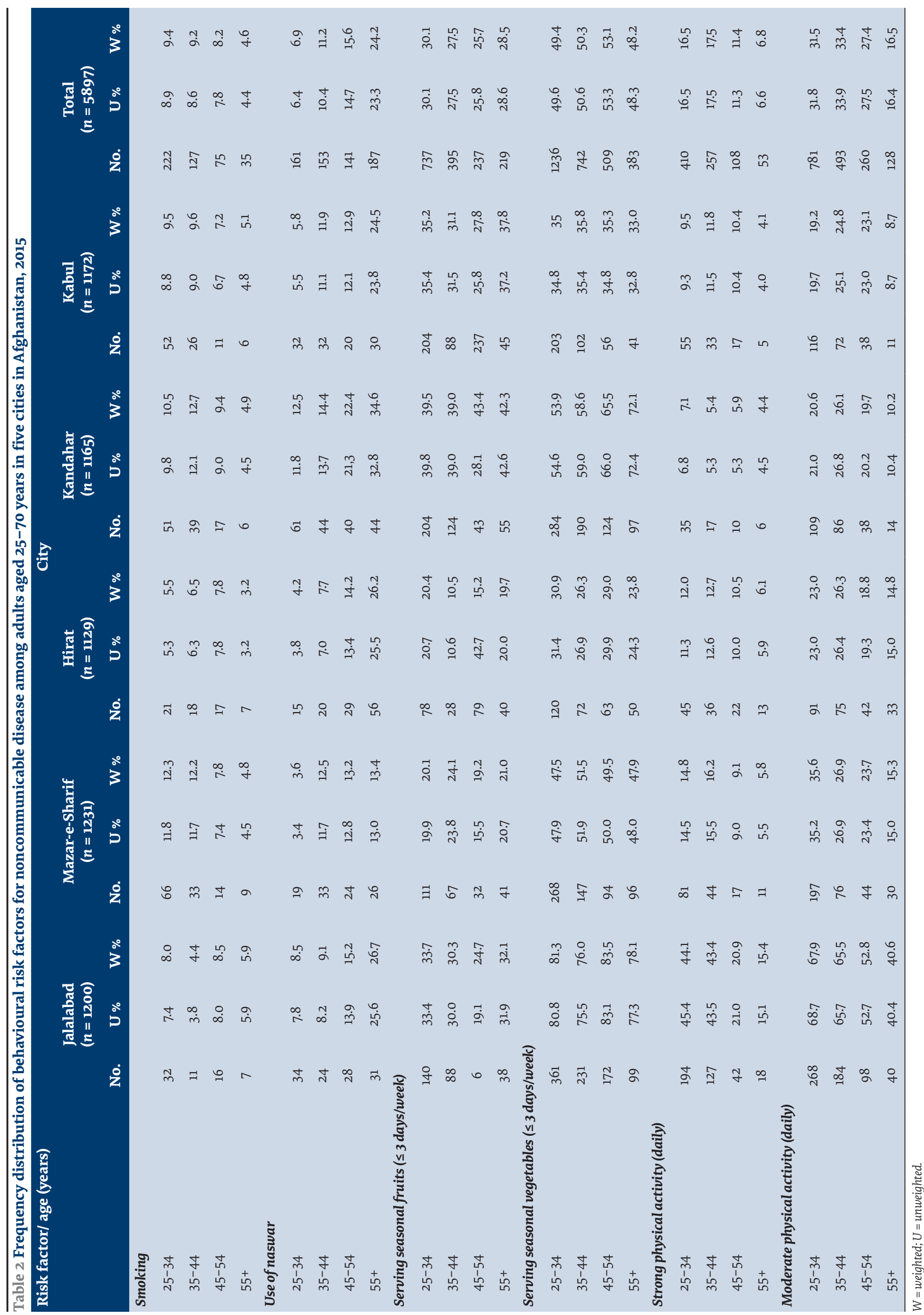


also common in $27.8 \%$ of respondents.

Daily work involving strong physical activity was less common (14.6\%) among reported responses while $29.5 \%$ practised moderate physical activity. As a whole, strong and moderate physical activity in the nature of work was more frequent in the youngest age group (16.5 and 31.8\%) and lowest in the oldest age group (6.6\% and $16.4 \%)$. The highest level of physical activity among all age groups was reported in Jalalabad.

\section{Physical measurements-STEP 2}

Table 3 shows the frequency of pathophysiological risk factors of study participants. Overall average of BMI was 25.95 (SD 5.7) kg/m². Mean BMI was higher among women than men $\left(26.84 \mathrm{~kg} / \mathrm{m}^{2}\right.$ vs $24.91 \mathrm{~kg} / \mathrm{m}^{2}(P<0.01)$. Overweight, obesity and central obesity were observed in $19 \%, 33.7 \%$ and $57.1 \%$ of participants. The highest rates for overweight and obesity were found in participants aged 45-54 and 35-44 years, respectively. However, the frequency of general and abdominal obesity was higher with age. The frequency of overweight/obesity was highest in the Jalalabad city $(59.6 \%)$ and lowest in Hirat city (47.5\%). Typically, $32.4 \%$ had high blood pressure, of this $23.5 \%$ of them were identified by physical measurement being not aware of their problems and the rest were under treatment. The frequency of high blood pressure was significantly higher among females (32.7\%) compared with males $(26.8 \%)$. The highest proportion of hypertension was recorded in Hirat city (35.6\%) and the lowest in Mazar-e-Sharif city (30.9\%).

\section{Biochemical measurement-STEP 3:}

The overall average proportion of participants who had raised blood sugar was $12.5 \%$, with the highest proportion in Kandahar city (22.4\%), much higher than the other cities: after removing the Kandahar data, the overall proportion was $10.0 \%$. The proportion was higher in females (13.1\%) than males (11.7\%), however, this was not statistically significant. Average (arithmetic mean) levels of fasting blood sugar, total glycerides, total cholesterol, high density lipoprotein (HDL) and low density lipoprotein (LDL) were 97.9 (SD 65.5) mg/dL, 164.5 (SD 89.4) mg/dL, 184.0 (SD 52.8) mg/dL, 45.1 (SD 20.8) mg/dL and 109.8 (SD 43.0) $\mathrm{mg} / \mathrm{dL}$ respectively. Mean fasting blood sugar levels increased with age in all provinces but did not differ between males and females. Similarly, averages for triglycerides, cholesterol, HDL and LDL did not differ between women and men (Table 4).

\section{Discussion}

Lack of information on risk factors for NCDs in Afghanistan has been a crucial challenge impeding policy-makers in generating advocacy and developing interventions for prevention and control. In this study, we found that the modifiable risk factors of NCDs were prevalent in the major cities, Kabul, Kandahar, Hirat, Jalalabad and Mazar-e-Sharif. High priority is given to infectious diseases, maternal health and nutrition $(32,33)$ while the burden of NCDs is gradually encumbering the fragile econ- omy of the country and its newly fledged health system. This report of findings from 5 provinces and analysis of the full database could be used as a proxy for national estimates of factors for NCDs, although further advanced study is still needed.

Several forms of tobacco consumption are prevalent among the Afghan population: cigarette smoking, shisha smoking, mouth and nose snuff, etc. Almost one-tenth of the adult population was using tobacco as snuff or as cigarettes. Consumption of tobacco was higher among men mainly due to the cultural unacceptability of women's use of tobacco in the country. Use of naswar was higher in the older age group while cigarette smoking was higher in younger section. The older generation have been using naswar for years while the new generation is oriented towards smoking. The low cost of naswar (tobacco-snuff) could be the reason for the greater use. Such differences are supported by other studies $(34,35)$. Sex differences in risk factors were also demonstrated in Karachi in Pakistan (36). It seems using tobacco (smoking or smokeless) is common in the country, which is consistent with reports from other low-income countries $(37)$. The frequency $(8.0 \%$ for cigarettes, $11.1 \%$ for naswar), however, seems very low compared with a study conducted in Kabul on smoking in men aged 15+ years: the proportion of smoking was estimated to be $35.2 \%$ (38); this may be due to sex and age difference in the study populations. Other studies in the Islamic Republic of Iran, Pakistan and India show a high proportion of smoking among men, 36.0\%, 23.4\%, 28.5\% respectively (39-41).

Consumption of fruits was less frequent per week while the frequency was better for vegetables on average. This could be due to low socioeconomic status and low literacy levels. The level of moderate physical activity was higher compared with strong physical activity in daily affairs. Physical inactivity is the fourth leading risk factor for global mortality and has major implications on NCDs, particularly cardiovascular diseases and general health. However low physical activity among our participants could be due to low awareness or the poor availability of open spaces and jogging areas in the cities. Our findings are supported by earlier research (42). There is a need to sensitize and actively promote physical activity in cities. Our findings show that one fifth of the adults in the 5 cities were obese, with more than two-thirds being overweight or obese, a situation that needs to be addressed by public health authorities. These findings are supported by other studies $(21,35,43,44)$. Females had a higher BMI and waist circumference than men, which puts them at higher risk of NCD. Abdominal obesity was another problem with high frequency in women. This could be related to cultural issues in the Afghan context such as access to physical exercise facilities and restriction of female movement outside the home. Besides the general low level of health literacy, the obese are considered healthy, so they are generally reluctant to lose weight.

Overall, almost one-third of our participants had hypertension, of whom just 10\% were aware and sought health services. This indicates a high unmet need for 

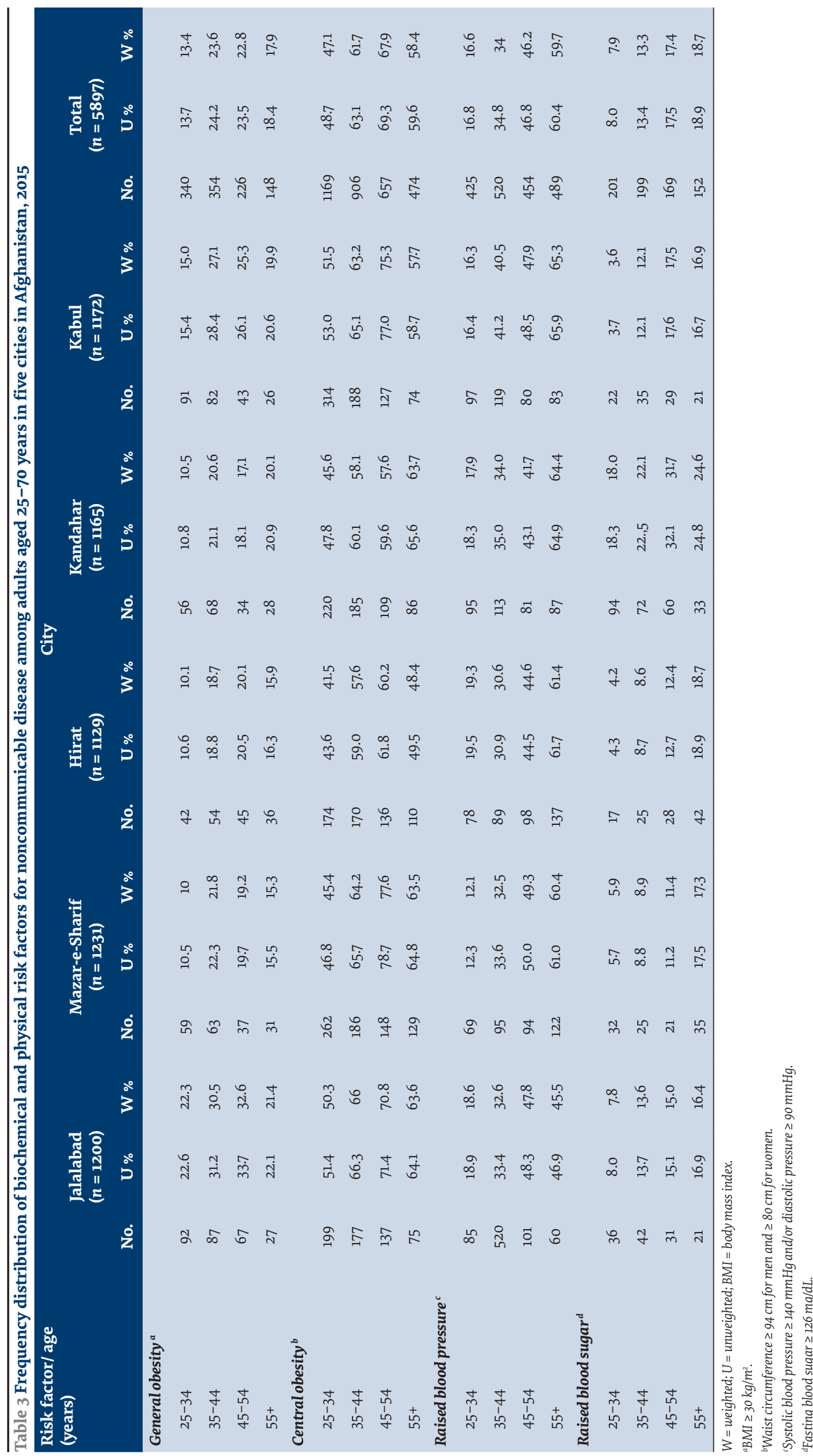


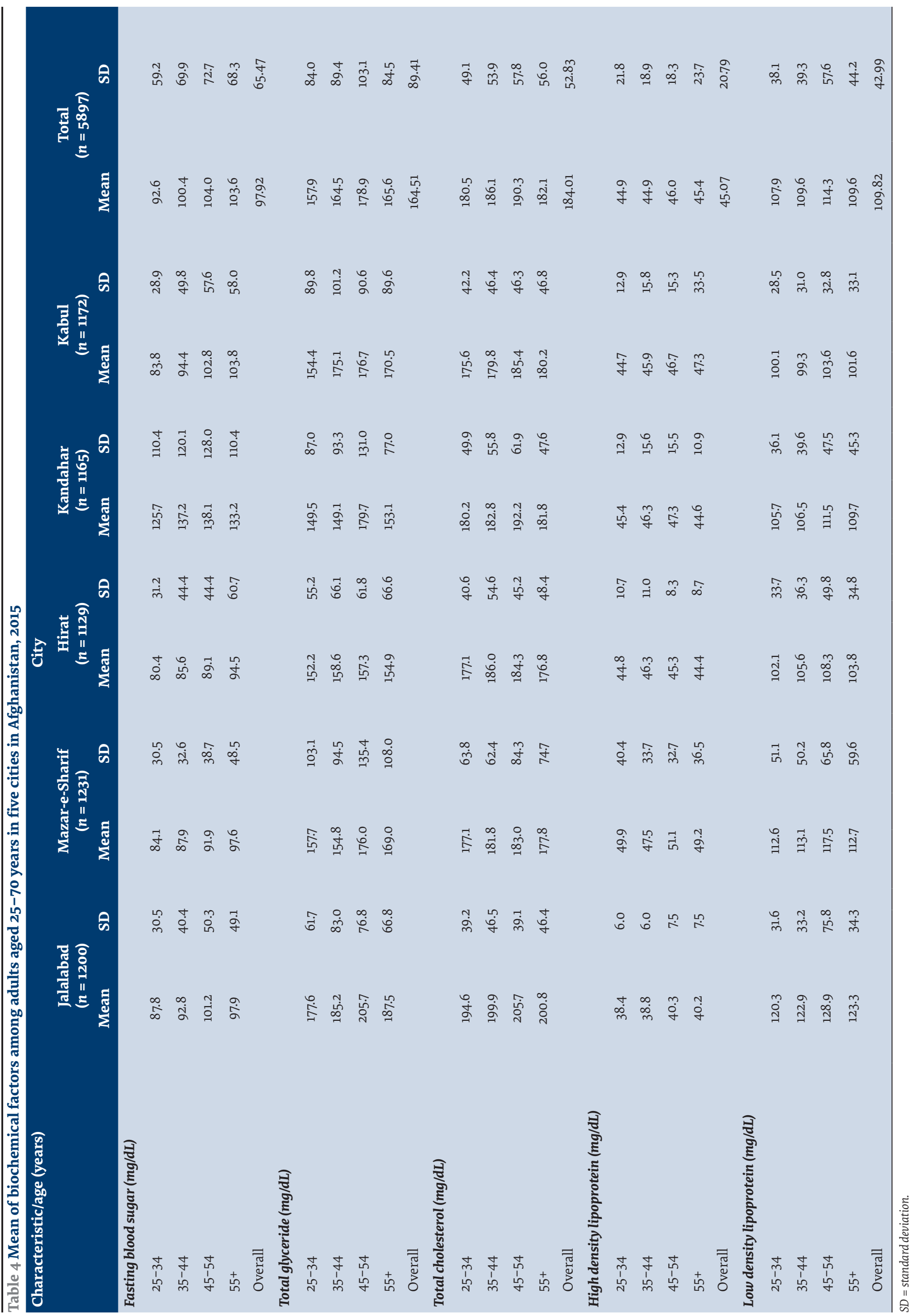


prevention and management of hypertension in the country. Raising awareness on hypertension and a screening programme should be encouraged when adults come to health centres for any other health problem. This finding is supported by an earlier study conducted in Kabul (22), and is consistent with studies in the Islamic Republic of Iran, Pakistan and Nepal (45-48). High level of raised blood sugar is another risk factor for other NCDs which was found as a result of this study. It is consistent with other studies within and outside the country $(22,47)$. Likewise, the high proportion of people in Kandahar with high blood sugar is a point for consideration. After removing the Kandahar data, the overall proportion was $10.0 \%$, thus, more advanced study is required in this city to identify the actual situation (the data were checked and the questionnaire reviewed for errors, however the possibility of non-fasting blood collection cannot be ruled out). Robust studies for diabetes are required in this southern city of the country.

This was a cross-sectional survey, therefore, it is not possible to establish causation. In addition, the surveys were conducted only in the urban setting of the provinces surveyed, therefore, our findings are representative only of the urban area of Afghanistan. The integrated and combined results, although reflected, are not adequately generalized to the general urban adult population as they were conducted over different time periods. Furthermore, the data were not standardized so caution should be used in interpretation of the findings. More than half the study participants $(52.2 \%)$ had $\geq 1$ of the 4 main risk factors (obesity, hypertension, smoking and high blood sugar). Therefore, taking into account the major findings of provincial as well as general overall estimates of risk factors, we encourage the introduction of education campaigns to raise awareness on physical activity and a healthy diet as protective factors against all NCDs.

Urbanization is expanding in Afghanistan and cities are progressively becoming overcrowded, however they have very limited facilities for jogging and other aerobic sports. The establishment of such facilitates, particularly for women, is recommended. As a number of risk factors may be present simultaneously in an individual, interventions are needed to target groups of risk factors rather than just one at a time. Although all provincial findings as well as the overall findings are alarming and will be useful as a baseline for future studies, the financial constraints which prevented listing of the households ahead of the study, the overestimation of the NCD burdens due to free checking of blood pressure and blood testing and the poor security situation, which forced the teams to exclude some areas, are further limitations to be taken into consideration.

Nonetheless, the findings of this study undoubtedly fill some of the gaps in the information for policy development and the design of interventions. Our findings pave the way for a nationwide study on NCDs using the WHO STEPwise approach to provide full information at country level. The establishment of behavioural surveillance using the STEPwise approach will place the Ministry of Public Health in a better position to take appropriate action.

\section{Acknowledgements}

We would like to thank the Surveillance Department at the Ministry of Public Health and the WHO Kabul Office for supporting the series of studies conducted at provincial level.

Funding: The funding for the primary studies in each province was provided by the WHO Country Office, but this study, which used the dataset of the primary studies, has not been funded by any organization.

Competing interests: None declared.

\section{Profil des facteurs de risque de maladies non transmissibles dans les principales villes d'Afghanistan : Approche STEPwise de l'OMS pour la surveillance \\ Résumé}

Contexte : Les maladies non transmissibles (MNT) constituent un problème de santé publique majeur dans le monde. Malgré l'amélioration de la situation sanitaire, les indicateurs de santé de l'Afghanistan sont les pires de la Région. Près de $37 \%$ d'adultes afghans décèdent du fait de MNT.

Objectifs : La présente étude avait pour objectif d'estimer la proportion des principaux facteurs de risque des MNT en Afghanistan.

Méthodes: Nous avons analysé l'ensemble de données des études menées dans cinq provinces (Balkh, Hirat, Kaboul, Kandahar et Nangarhar) au cours de la période comprise entre 2013 et 2015, en utilisant l'approche STEPwise de l'OMS pour la surveillance des MNT. Cela impliquait un échantillonnage en grappes à plusieurs degrés auprès de citoyens urbains âgés de 25 à 70 ans. Les logiciels EpiInfo, version 7, et SPSS, version 20, ont été utilisés pour la gestion des données.

Résultats : Au total, 5897 fiches ont été incluses dans l'analyse ; 54 \% concernaient des femmes. L'âge moyen était de 39,56 ans (écart type 12,29); le taux d'analphabétisme était de 61,5\% et 83,2 \% étaient mariés. Le tabagisme et l'usage du 
tabac à priser étaient de $8 \%$ et 11,1\% respectivement. En moyenne, les sujets consommaient des fruits et des légumes 2,76 et 3,85 jours par semaine et le surpoids, l'obésité générale et abdominale étaient de $19 \%, 33,7 \%$ et $57,1 \%$, respectivement. En règle générale, $32,4 \%$ avaient une pression artérielle élevée et $12,5 \%$ avaient une glycémie élevée.

Conclusions: Les facteurs de risque modifiables des MNT étaient répandus dans les principales villes du pays. Leur identification est vitale pour tenter de se concentrer sur la prévalence de ces maladies dans les villes urbaines. Des interventions sur mesure sont nécessaires pour se concentrer sur les MNT en Afghanistan.

$$
\begin{aligned}
& \text { مرتسم عو امل الخطر المتعلقة بالأمر اض غير السارية في المدن الكبرى في أفغانستان: نهج منظمة الصحة العالمية للترصد التدريبي }
\end{aligned}
$$

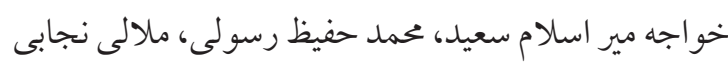

$$
\begin{aligned}
& \text { الخلاصة }
\end{aligned}
$$

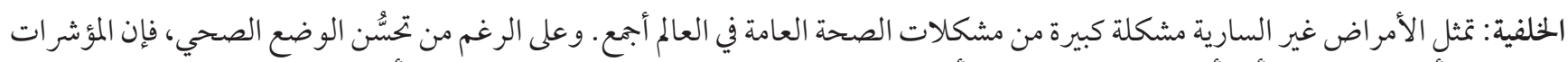

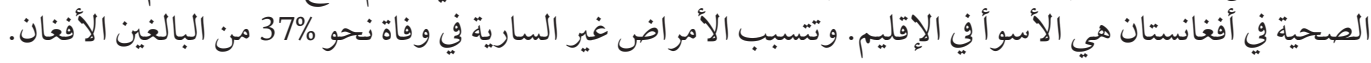

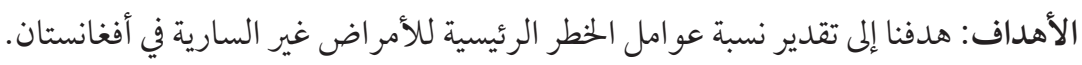

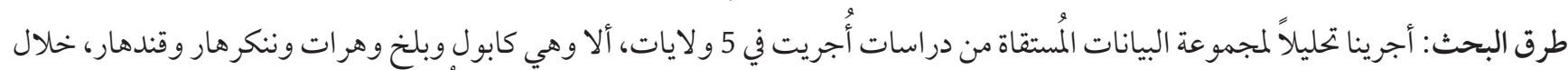

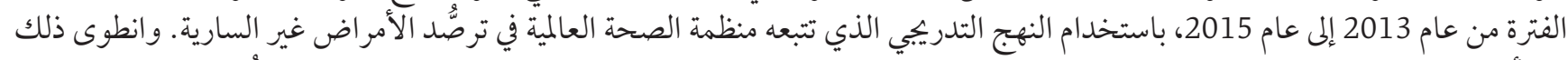

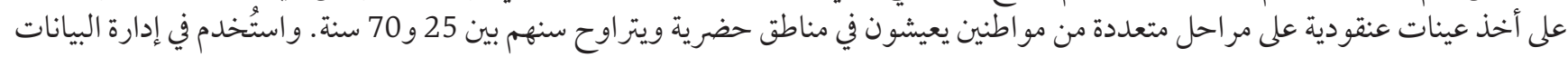

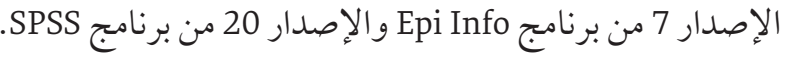

\section{References}

1. Population estimation 2014/15. Kabul: Central Statistics Organization; 2015 (http://cso.gov.af/en/ page/demography-and-socile-statistics/demograph-statistics/3897, accessed 29 July 2015).

2. Afghanistan Demographic and Health Survey 2015. Kabul: Central Statistics Organization, Ministry of Public Health; 2015.

3. Maurice J. WHO heads efforts to restore Afghanistan's shattered health. Bull World Health Organ. 2001;79(12):1174. PMID:11799458

4. Mayhew M, Hansen PM, Peters DH, Edward A, Singh LP, Dwivedi V, et al. Determinants of skilled birth attendant utilization in Afghanistan: A cross-sectional study. Am J Public Health. 2008 Oct;98(10):1849-56. doi:10.2105/AJPH.2007.123471

5. World drug report - executive summary. New York: United Nations Office on Drugs and Crime; 2015:42.

6. Afghanistan mortality survey 2010. Calverton, Maryland: Afghan Public Health Institute, Ministry of Public Health, Central Statistics Organization (Afghanistan), ICF Macro, Indian Institute of Health Management Research, World Health Organization Regional Office for the Eastern Mediterranean; 2011 (http://dhsprogram.com/pubs/pdf/FR248/FR248.pdf, accessed 20 December 2019).

7. Horton R. Non-communicable diseases: 2015-2025. Lancet. 2013 Feb 16;381(9866):509-10. doi:10.1016/So140-6736(13)60100-2

8. Global status report on noncommunicable diseases 2014. Geneva: World Health Organization; 2014.

9. Foucard L. Transition épidémiologique et développement: l'essor des maladies non transmissibles est-il une fatalité? [Epidemiological transition and development: is the increase in non-communicable diseases inevitable?] Médecine Tropicale: revue du corps de santé colonial. 2007;67(6):543-4.

10. 2008-2013 action plan for the global strategy for the prevention and control of noncommunicable diseases. Geneva: World Health Organization; 2008 (World Health Assembly document A61/8).

11. Global Health Observatory data: NCD mortality and morbidity. Geneva: World Health Organization; 2017 (www.who.int/gho/ncd/ mortality_morbidity/en/, accessed 29 January 2018). 
12. Global health estimates: deaths by cause, age, sex and country, 2000-2012. Geneva: World Health Organization; 2014.

13. WHO Fact sheet. Noncommunicable diseases. Updated, June 2017. Geneva: World Health Organization; 2017 (www.who.int/ mediacentre/factsheets/fs355/en/, accessed 1 September 2017).

14. Global status report on noncommunicable diseases 2010. Geneva: World Health Organization; 2011 (http://www.who.int/nmh/ publications/ncd_report_full_en.pdf, accessed 29 July 2015).

15. Kankeu HT, Saksena P, Xu K, Evans DB. The financial burden from noncommunicable diseases in low- and middle-income countries: a literature review. Health Res Policy Syst. 2013 Aug 16;11:31. doi:10.1186/1478-4505-11-31

16. The political declaration of the United Nations General Assembly on the prevention and control of non-communicable diseases: commitments of Member States and the way forward. Technical discussion paper. Fifty-ninth session of the Regional Committee for the Eastern Mediterranean, August2012. Provisional agenda item 4(a) (EM/RC59/3) (http://applications.emro.who.int/docs/ RC_technical_papers_2012_3_14578_EN.pdf, accessed 29 July 2015).

17. Salehuddin M, Choudhury KN, Islami N, Zillurahman M, Gosh S, Majib M. Burden of non-communicable diseases in South Asia - a clinical review. University Heart J. 2010, July;6(2).

18. Health systems strengthening in countries of the Eastern Mediterranean Region: challenges, priorities and options for future action. Technical discussion paper. Fifty-ninth session of the Regional Committee for the Eastern Mediterranean, October 2012. Cairo: World Health Organization; 2012 (EM/RC59/Tech.Disc.1) (http://applications.emro.who.int/docs/RC_technical_papers_2012_Tech_Disc_1_14613_EN.pdf, accessed 20 December 2013).

19. Prevention and control of noncommunicable diseases. Outcome of the high-level meeting of the General Assembly on the prevention and control of noncommunicable diseases and the first global conference on health lifestyles and noncommunicable disease control. Sixty-fifth World Health Assembly, 20 April 2012. Provisional agenda item 13.1 (A65/6). Geneva: World Health Organization; 2012 (http://apps.who.int/gb/ebwha/pdf_files/WHA65/A65_6-en.pdf, accessed 20 December 2019).

20. Noncommunicable diseases country profiles 2014. Geneva: World Health Organization; 2014 (https://www.who.int/nmh/publications/ncd-profiles-2014/en/, accessed 20 December 2019).

21. Diabetes programme. Country and regional data on diabetes. Prevalence of diabetes in the WHO Eastern Mediterranean Region. Geneva: World Health Organization; 2015 (http://www.who.int/diabetes/facts/world_figures/en/index2.html, accessed 20 December 2019).

22. Mohmand KA, Sharifi K, Bahram AA. Smoking prevalence survey in Kabul City. Kabul. Social and Health Development Program; 2010. Afghan J Public Health. 2014;2(1):21-5. (http://anpha.af/wp-content/uploads/2016/10/afjph_2014_volume_2_issue_1-2.pdf, accessed 15 January 2020).

23. Saeed KMI. Prevalence of risk factors for NCDs in the adult population of urban areas in Kabul city, Afghanistan. Cent Asian J Glob Health. 2013;2(2):10. 5195/cajgh.2013.69

24. Ministry of Public Health, National Health Policy (2015-2020), Kabul Afghanistan

25. Bonita R, deCourten M, Dwyer T, Jamrozik K, Winkelmann R. Surveillance of risk factors for noncommunicable diseases: the WHO STEP-wise approach. Geneva: World Health Organization; 2002 (WHO/NMH/CCS/01.2002).

26. WHO STEPwise approach to surveillance (STEPS). Geneva: World Health Organization; (http://www.who.int/chp/steps/en, accessed 20 December 2019)

27. Riley L, Guthold R, Cowan M, Savin S, Bhatti L, Armstrong T, et al. The World Health Organization STEP wise approach to noncommunicable disease risk-factor surveillance: methods, challenges, and opportunities. Am J Public Health. 2016;106:74-8. doi:10.2105/AJPH.2015.302962

28. Obesity: preventing and managing the global epidemic. Geneva: World Health Organization; 2000 (WHO Technical Report Series No. 894).

29. The IDF consensus worldwide definitions of the metabolic syndrome. Brussels: International Diabetes Federation; 2006 (http:// www.idf.org/webdata/docs/IDF_Meta_def_final.pdf, accessed 29 July 2015).

30. Whitworth JA; World Health Organization, International Society of Hypertension Writing Group. 2003 World Health Organization (WHO)/International Society of Hypertension (ISH) statement on management of hypertension. J Hypertens. 2003 Nov;21(11):1983-92. doi:10.1097/00004872-200311000-00002

31. Diabetes. Fact sheet no. 312. Updated January 2015. Geneva: World Health Organization; 2015 (http://www.who.int/mediacentre/ factsheets/fs312/en/, accessed 29 July 2015).

32. Health management information system (HMIS). In: Annual report 1391. Kabul: Ministry of Public Health; 2012.

33. Disease early warning system (DEWS) surveillance. In: Annual report. Kabul: Afghan National Public Health Institute, Ministry of Public Health; 2013.

34. WHO STEPS. Chronic disease risk factor surveillance. Data book, I.R. Iran 1388 (2009) (http://www.who.int/chp/steps/Iran_DataBook_2009.pdf?ua=1, accessed 29 July 2015).

35. Pan B, Chen X, Wu X, Li J, Li J, Li Y, et al. Prevalence of noncommunicable diseases and their risk factors in Guangzhou, China. Prev Chronic Dis. 2014 Mar 27;11:E49. doi:10.5888/pcd11.130091

36. Stevens GA, Singh GM, Lu Y, Danaei G, Lin JK, Finucane MM, et al. National, regional, and global trends in adult overweight and obesity prevalence. Popul Health Metr. 2012;10(1):22-2. doi:10.1186/1478-7954-10-22 
37. Kebede Y, Abula T, Ayele B, Feleke A, Degu G, Kifle A, et al. Substances abuse for the Ethiopian health center team. Ethiop Public Health Train Initiative. 2005;81.

38. Mohmand KA, Sharifi K, Ahad Bahram A. The burden of cigarette smoking among males in Kabul, Afghanistan. Afghan J Public Health. 2014 January;(2):1.

39. Alam SE. Prevalence and pattern of smoking in Pakistan. J. Pak. Med. Assoc. 1998 March;64-66.

40. Meysamie A, Ghaletaki R, Haghazali M, et al. Pattern of tobacco use among the Iranian adult population: results of the national Survey of Risk Factors of Non-Communicable Diseases (SuRFNCD-2007). Tob Control. 2010;19(2):125-128. doi:10.1136/ tc.2009.030759.

41. E Jindal SK, Aggarwal AN, Chaudhry K, et al. Tobacco smoking in India: Prevalence, quit-rates and respiratory morbidity. Indian J Chest Dis Allied Sci. 2006;48(1):37-42.

42. Nath A, Garg S, Deb S, Ray A, Kaur R. A study of the profile of behavioral risk factors of non-communicable diseases in an urban setting using the WHO STEPS 1 approach. Ann Trop Med Public Health. 2009;(2):15-9.

43. Finucane MM, Stevens GA, Cowan MJ, Danaei G, Lin JK, Paciorek CJ, et al. Nnational, regional, and global trends in body-mass index since 1980: systematic analysis of health examination surveys and epidemiological studies with 960 country-years and 9.1 million participants. Lancet. 2011 Feb 12;377(9765):557-67. doi:10.1016/So140-6736(10)62037-5

44. Garg A, Anand T, Sharma U, Kishore J, Chakraborty M, Ray PC, et al. Prevalence of risk factors for chronic noncommunicable diseases using who STEPS approach in an adult population in Delhi. J Family Med Prim Care. 2014 Apr-Jun;3(2):112-8. doi:10.4103/2249-4863.137617

45. Haghdoost AA, Sadeghirad B, Rezazadehkermani M. Epidemiology and heterogeneity of hypertension in Iran: a systematic review. Arch Iran Med. 2008 Jul;11(4):444-52.

46. Esteghamati A, Meysamie A, Khalilzadeh O, Rashidi A, Haghazali M, Asgari F, et al. Third national surveillance of risk factors of NCDs (SuRFNCD-2007) in Iran: methods and results on prevalence of diabetes, hypertension, obesity, central obesity, and dyslipidemia. BMC Public Health. 2009;9:167. PMID:19480675.

47. Shera AS, Basit A, Fawwad A, Hakeem R, Ahmedani MYM, Zafar M. Pakistan national diabetes survey: prevalence of glucose intolerance and associated factors in the Punjab province of Pakistan. Prim Care Diabetes. 2010;4(2):79-83. doi:10.1016/j. pcd.2010.01.003

48. Aryal KK, Mehata S, Neupane S, Vaidya A, Dhimal M, Dhakal P, et al. The burden and determinants of non communicable diseases risk factors in Nepal: findings from a nationwide STEPS survey.PLoS ONE. 2015;10(8): e0134834. doi:10.1371/journal. pone. 0134834 